\title{
Contingency planning in southern Africa: Events rather than processes?
}

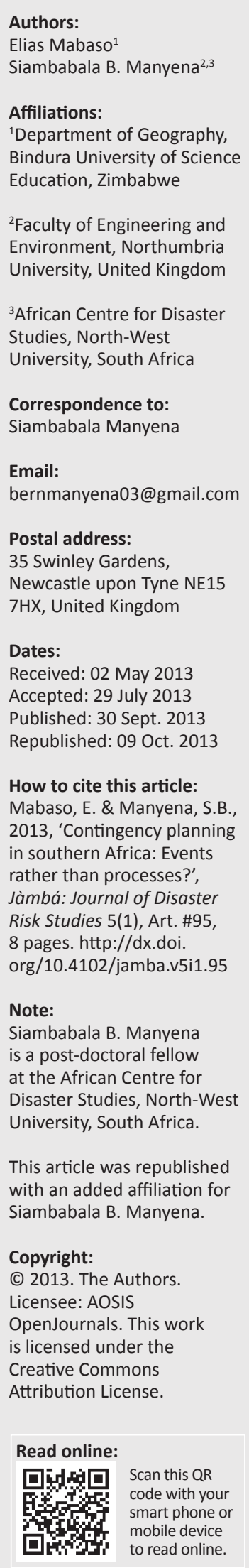

With the increasing frequency, magnitude and impact of disasters, there is growing focus on contingency planning as a tool for enhancing resilience. Yet, there is little empirical evidence that reflects on the practice of contingency planning systems within the context of disaster risk reduction. This article explores the practice of contingency planning in southern Africa, focussing on Malawi, Mozambique, Namibia, Zambia and Zimbabwe. A qualitative comparative analysis informed by fieldwork was used. The findings show that (1) there was a wide gap between theory and practice in contingency planning, (2) response activities rarely reflected projected scenarios and (3) resources were inadequate for effective contingency planning. We conclude that unless these issues are addressed, contingency planning is likely to remain a theoretical rather than a practical tool for building disaster-resilient communities in southern African countries. Although a generalisation cannot be made on the status of contingency planning and practice in southern Africa without a wider analysis of more examples, the findings may apply beyond the examined contexts and also offer insights into research gaps.

\section{Introduction}

It is an auspicious time to be increasing our efforts towards contingency planning in southern Africa considering the surge in loss of life, livelihoods and hard-won development resulting from disasters. With climate change likely to increase further the frequency and magnitude of hydrometeorological hazards in southern Africa, contingency planning is a key tool for enhancing resilience to disasters (Choularton 2007). This article explores the nature of contingency planning, related gaps and their effects on coordinated preparedness and response capacity in southern Africa, focusing on Malawi, Mozambique, Namibia, Zambia and Zimbabwe. The study sought answers to the following questions:

- To what extent do contingency planning processes address challenges of coordinated response to disasters in southern Africa?

- In what ways has contingency planning strengthened disaster preparedness in southern Africa?

- What are some of the gaps in contingency planning processes in southern Africa?

The article is based on primary and secondary data that were collected from the five mentioned countries. This article is timely considering the currency of disaster risk reduction across the world. It can make a significant contribution to our knowledge in contingency planning, particularly considering that there is limited empirical evidence about the status of contingency planning in southern Africa. As an introduction, the article conceptualises contingency planning. This is followed by the methodology used in the case study, focusing on the data collection methods and tools. The results are then outlined and discussed. Finally, we acknowledge that contingency planning tends to be a complex process. Southern African countries should shift from viewing contingency planning as an event that produces a document that gathers dust on a shelf to approaching it as a plan of action that affected communities can embrace, thus enhancing their resilience to disasters.

\section{Conceptualising contingency planning}

With the predicted increase in frequency, magnitude and impact of disasters, particularly those triggered by hydro-meteorological hazards resulting from climate change, contingency planning is important for at least three reasons. Firstly, contingency planning is one of the elements of disaster preparedness and response planning that is amongst the five priority areas for disaster risk reduction as outlined in the Hyogo Framework for Action 2005-2015 (HFA), which was adopted by 168 nations in Japan in 2005. The HFA is the global framework and guidance on disaster risk reduction. It adopts a systematic effort to analyse and manage the causal factors of disasters, including reduced exposure to hazards, lessened vulnerability of people and property, sound management of land and the environment, and improved preparedness for adverse 
events (United Nations International Strategy for Disaster Reduction [UNISDR] 2009).

Secondly, contingency planning can provide a holistic picture of disaster risk reduction by bringing together the major elements of the disaster: risk, hazard and vulnerability. The relationship between these three elements is expressed using the most cited disaster equation (Blaikie et al. 1994):

Risk $=$ Hazard $\times$ Vulnerability

[Eqn 1]

where, according to the UNISDR (2009):

- risk is the combination of the probability of an event and its negative consequences

- hazard is a dangerous phenomenon that may cause loss of life, injury or other health impacts, property damage, loss of livelihoods and services, social and economic disruption, or environmental damage

- vulnerability refers to the characteristics and circumstances of a community, system or asset that make it susceptible to the damaging effects of a hazard.

Thus, contingency planning processes address risks through a process of hazard identification and prioritisation, identifying vulnerable elements as well as the capacity of affected people and responders in case the hazard degenerates into a disaster. For example, if a flood hazard is likely to affect an area, there is a need to determine the possible magnitude of the flood, likely areas and populations to be affected, and livelihoods at risk before suggesting response measures.

Thirdly, contingency planning is one of the key tools for enhancing resilience or the capacity of a community potentially exposed to hazards to 'bounce forward' (Manyena et al. 2011) by adapting, resisting or changing to reach and maintain an acceptable level of functioning and structure (UNISDR 2005).

However, the term 'contingency planning' is hard to define, as it means different things to different people (Schedler 2007). We consider three definitions here. Choularton (2007:3) defines contingency planning as 'a process in anticipation of potential crises, of developing strategies, arrangements and procedures to address the humanitarian needs of those adversely affected by a crisis'. Eriksson and McConnell's (2011) definition is more elaborate. They view contingency planning as a process leading towards the prior allocation of resources, personnel, equipment, crisis control rooms, tasks, responsibilities and decision guidance or rules. This is coupled with training, scenario planning and an array of simulation exercises in a 'safe' environment to ensure that the operational and political-strategic layers within public authorities are best placed to manage any crisis that emerges. Finally, the UNISDR (2007) defines a contingency plan as a management process that analyses specific potential events or emerging situations that might threaten society or the environment and establishes arrangements in advance to enable timely, effective and appropriate responses to such events and situations.

The UNISDR (2007) further states that contingency planning is part of the overall preparedness that often results in organised and coordinated courses of action, with clearly identified institutional roles and resources, information processes and operational arrangements for specific actors at times of need. Choularton (2007) states that since contingency planning is a forward-looking undertaking in the imminence of a disaster, it is one of the components of preparedness planning; it does not equate to comprehensive preparedness planning. In other words, a contingency plan addresses shortterm planning when a disaster is imminent to prepare society to respond. The intention of contingency planning, according to Choularton (2007) is to minimise casualties by addressing possible gaps that were not easily discernible during the long-term preparedness planning. As events unfold and responders get more information on what is likely to happen, and the extent and likely location of events, a contingency plan is drafted to address specific events (Harrald \& Mazzuchi 1993). In contrast, comprehensive preparedness planning is not prompted by an imminent disaster but considers all possible disasters, mostly based on historical records and other projected threats that are likely to occur (Choularton 2007). Choularton (2007) further states that comprehensive preparedness planning addresses broader issues that include institutional and legislative framework, policies and resource allocation.

Harrald and Mazzuchi (1993) emphasise the importance of scenarios as tools for successful contingency planning, particularly in identifying gaps in resource mobilisation and exercising. The most common approach to scenario building in contingency planning is the best, most-likely or middle and worst-case scenario approach. Scenarios are developed to allow planners to examine and plan for different scales of the same potential crisis or emergency. Table 1 provides examples of the best-case, middle-case and worst-case scenarios for drought, flooding and earthquakes.

Harrald and Mazzuchi (1993) further state that scenarios of possible emergency conditions allow key actors to envision,

TABLE 1: Best-case, middle-case and worst-case scenarios for flood, drought and earthquakes.

\begin{tabular}{llll}
\hline Scenario & Drought & Flood & Earthquake \\
\hline Best & No drought & Normal seasonal flooding & $\begin{array}{l}\text { Earthquake measuring up to } 4.5 \text { on the Richter scale, causing } \\
\text { minor damage in rural areas }\end{array}$ \\
Most likely & $\begin{array}{l}\text { Moderate drought affecting one part of the } \\
\text { country }\end{array}$ & $\begin{array}{l}\text { Major flood, affecting up to } 100000 \\
\text { people }\end{array}$ & $\begin{array}{l}\text { Earthquake measuring up to 6.5 on the Richter scale, causing } \\
\text { major damage in rural areas, including medium-sized towns }\end{array}$ \\
$\begin{array}{l}\text { Worst } \\
\text { county }\end{array}$ & $\begin{array}{l}\text { Extreme flood, affecting up to } 1000 \text { 000, } \\
\text { including people in the capital city }\end{array}$ & $\begin{array}{l}\text { Earthquake measuring up to 8.0 on the Richter scale with an } \\
\text { epicentre in a major city, causing catastrophic damage }\end{array}$ \\
\hline
\end{tabular}

Source: Choularton, R., 2007, Contingency planning and humanitarian action: A review of practice, Overseas Development Institute, London, p. 13 
anticipate and solve problems that can arise during crises through regular updates and exercises. Whilst it does not specifically address long-term recovery issues, contingency planning contributes towards building resilience by addressing some of the drivers of vulnerability, such as the reduction of negative impacts of a disaster on livelihoods.

The three introduced definitions (Choularton 2007; Eriksson \& McConnell 2011; UNISDR 2009) suggest that contingency planning has at least six characteristics:

- it is a continuous process rather than an event that leads to the production of documents that risk gathering dust on the office shelves or being locked in a cabinet or filed on a computer

- it is based on preparedness and response policy guidelines

- it leads to early response as the potential crisis tends to be anticipated on the basis of scenarios generated within realistic parameters

- it involves preparedness planning, such as regular training, exercises and simulations to validate the contingency plans

- it requires identifying gaps and mobilisation of resources, including financial, human and material resources

- it adopts a multidisciplinary, multisectoral and inclusive participatory approach that involves individuals, teams, organisations and communities with clear coordination mechanisms, roles and responsibilities.

The outcome of contingency planning is an action plan that can be implemented once a disaster occurs. Unlike disaster risk management planning, which tends to be long term and cover a whole range of hazards based on historical trends, contingency planning is forward planning in a state of uncertainty and formulated to address an emerging crisis (United Nations High Commissioner for Refugees 2003). Thus, contingency plans attempt to answer the 'what if' question based mostly on scenario planning to address possible gaps in a risk management plan. It might be viewed as an alternative plan or 'plan B' to be put in action when needed or if the primary plan (normally the risk management plan) fails. This study examines whether there is any evidence that southern African countries fulfil the basic characteristics of contingency planning to ensure an effective response to crises.

\section{Disaster context of southern Africa}

Southern Africa generally falls under the Southern African Development Community (SADC), one of Africa's five regional economic commissions. The SADC has 15 member states. ${ }^{1}$ According to the United Nations Development Programme (2012), southern Africa is prone to a variety of natural hazards and related disasters such as drought, floods, cyclones, fires, earthquakes, landslides, livestock diseases, pest infestations and epidemics, which reinforces the need for contingency planning.

1.Angola, Botswana, Democratic Republic of Congo, Lesotho, Madagascar, Malawi, Mauritius, Mozambique, Namibia, Seychelles, South Africa, Swaziland, Tanzania, Zambia and Zimbabwe.
Climate change is expected to further increase hydrometeorological hazards in the region. The temperatures in southern Africa are expected to warm by between $1.0{ }^{\circ} \mathrm{C}$ and $3.0{ }^{\circ} \mathrm{C}$ by 2080 (SADC 2012). As a result of warmer temperatures, diseases such as malaria are likely to spread to places where it was not previously endemic and increased heat stress to natural ecosystems and agricultural crops are likely to impact negatively on the productivity of rangeland, grazing and food production (SADC 2012). Similarly, since 1950, southern Africa has witnessed a downward trend in rainfall and an increase in cyclone activity in the south western Indian Ocean region (SADC 2012). According to the International Council for Science (ICSU) (2007), about 59\% of the disasters experienced between 1997 and 2007 in southern Africa were related to hydro-meteorological hazards, mostly floods, cyclones and droughts. The southern African region has been struck by four major droughts in recent decades: 1991-1992, 1994-1995, 2000-2001 and 2005-2006.

The worst floods struck in 2000, which affected eight countries in southern Africa. More than 700 lives were lost in Mozambique alone, with material loss estimated at \$500 million (ICSU 2007). When the floods occurred, barely any of the affected countries had contingency plans. By the end of 2011, all countries in southern Africa had at least some form of a contingency plan for identified priority hazards, ranging from flood contingency plans to cholera contingency plans.

Seismic risk could be another justification for contingency planning in southern Africa, particularly for countries along the Rift Valley, stretching from Eritrea through Malawi to Mozambique. Along the Rift Valley and on Indian Ocean islands, several volcanoes are known to be active, including Mount Nyiragongo in the Democratic Republic of Congo and Mount Karthala on the island of Comoros.

These hazards, combined with vulnerabilities, have the potential to cause disasters (Blaikie et al. 1994). The major vulnerabilities include food insecurity, HIV and AIDS, population growth, urbanisation, land degradation, inequalities with regard to gender, education, health and wealth and poor governance (SADC 2012).

\section{The case study area}

This study focused on the Zambezi River basin, which extends across five countries affected mostly by hydro-meteorological hazards such as floods, droughts and cyclones (Figure 1).

The countries are Malawi, Mozambique, Namibia, Zambia and Zimbabwe. These countries were chosen because (1) the authors had field experience in all five countries, specifically with regard to coordinating preparedness and response to floods and (2) the countries were amongst the first in the region to compile contingency plans.

\section{Methodology}

This study adopted a qualitative comparative analysis to capture similarities and differences (Ragin 1987) in 


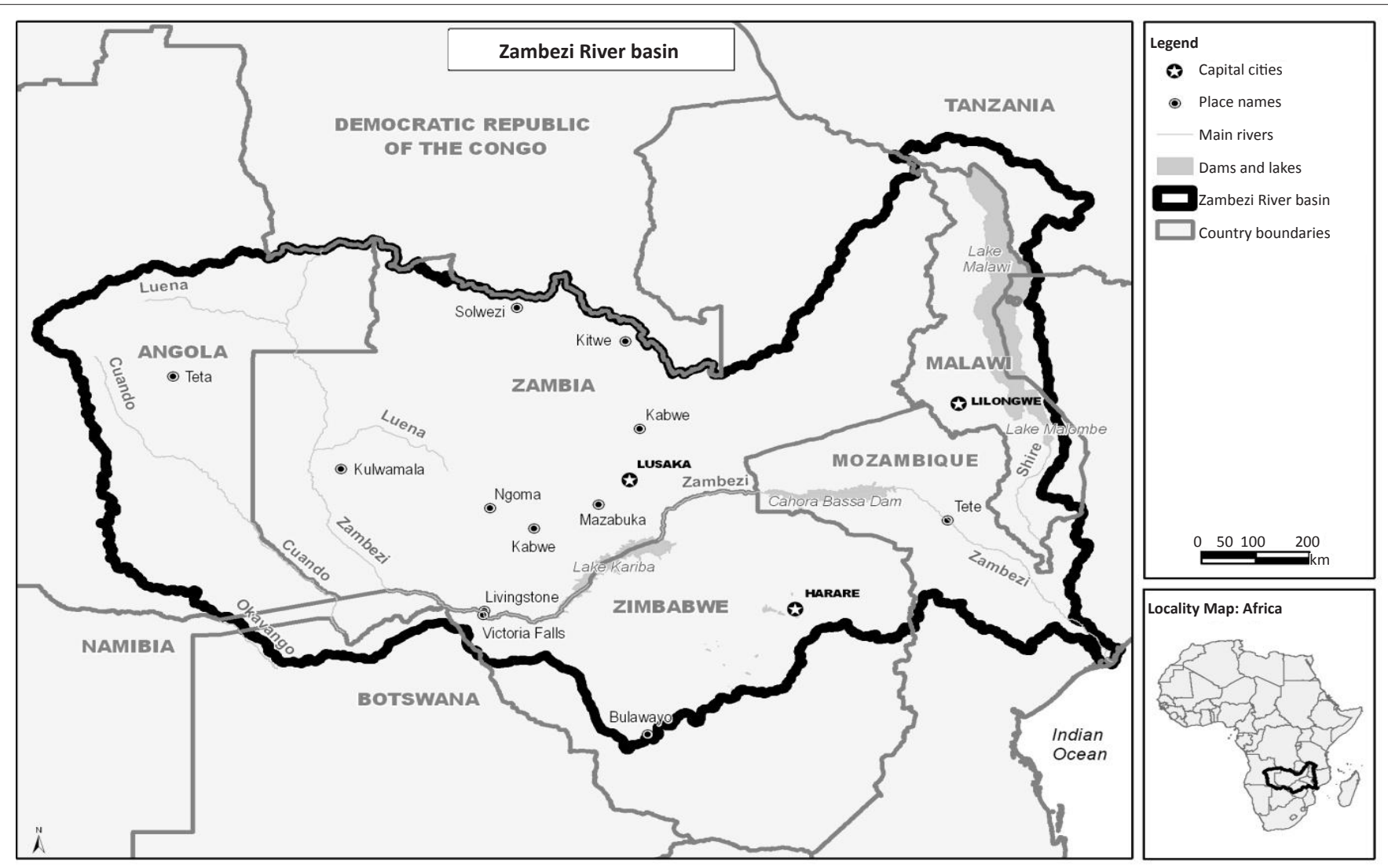

Source: Office for the Coordination of Humanitarian Affairs, Regional Office for Southern Africa (OCHA-ROSA), 2012, OCHA, Johannesburg

FIGURE 1: Zambezi River basin.

contingency planning processes and practices in Malawi, Mozambique, Namibia, Zambia and Zimbabwe. The study did not emphasise universality and causality used to make the kind of generalisations that have dominated disaster risk reduction theory. Rather, the study focused on identifying recurring patterns, variations and inconsistencies in contingency planning processes. To this end, the five countries were selected using the maximum variation or heterogeneity sampling strategy that 'aims at capturing and describing the central themes that cut across a great deal of variation' (Patton 2002:234-235). This sampling strategy also enabled us to explore a wide range of issues to capture 'multiple realities' (Guba \& Lincoln 2005; May 2011; Sarantakos 2006). However, one of the major challenges of qualitative comparative analysis is to determine comparable units of analysis (Patton 2002). To address this weakness, we derived a range of topics from contingency planning literature. These included policy guidelines, hazard and vulnerability assessments, scenarios, plan development and validation, resources, approaches and response. These themes later informed the data analysis.

Data were collected from at least three sources. Firstly, an extensive review of all contingency plans from the five countries was performed. These included the contingency plans compiled in 2006-2007 and the latest plans (20112012) for the selected countries. Secondly, regional seasonal forecasts from 2006 and country-specific downscaled forecasts were analysed to determine whether hazard analysis and scenario development reflected seasonal forecasts. Seasonal weather forecasts give an indication of expected weather for the season and it is possible for countries to identify areas likely to receive above-normal rainfall that may lead to flooding. Where available, hydrological information was also reviewed to determine how it was used in risk determination. Finally, data were collected from discussions and observations during the development of contingency plans in the respective countries. In most cases, this was followed by 'lessons learned' exercises and reviews of the contingency plans in Malawi, Namibia, Zambia and Zimbabwe.

Data analysis was organised according to themes (see later) to compare and contrast items assigned to the same theme. Consistent with literature, this involved an iterative process to generate a compact summary of the data (Harding 2013). The major limitation of the study was that generalisations cannot be made simply on five examples without a comprehensive analysis of many more examples from southern Africa. However, the findings may resonate with contingency planning processes and practices in some contexts and offer insights into further areas of research.

\section{Research findings and discussion}

This section presents and discusses the findings of the study. It is divided into three broad themes: contingency planning and coordination issues; contingency planning and preparedness strengthening and gaps in contingency planning. 


\section{Contingency planning processes and coordination issues}

The contingency planning process varies across the countries that were studied. With the exception of Mozambique and Zambia, contingency planning takes the form of an event rather than a continuous systematic process to enhance preparedness and response. Nonetheless, in all five the examples, the government often takes the lead in coordinating the contingency planning process at national level with support from partners, mostly the United Nations and non-governmental organisations (NGOs). However, at sub-national level, only Mozambique has well-developed regional contingency plans. Hardly any provincial or district contingency plans exist in Zambia and Zimbabwe. Malawi has rarely updated district contingency plans. Namibia has regional contingency plans, but at the time of this study the national contingency plan was going through an approval process.

In Mozambique, the National Institute for Disaster Management coordinates most of the key aspects of disaster preparedness and response and leads the process of contingency planning. The planning process begins at district and provincial level and culminates into a national contingency plan (Government of Mozambique 2008). This strengthens vertical linkage and coordination between national and lower levels during preparedness and response.

In contrast to the Mozambican contingency planning framework, contingency planning is highly centralised in Malawi and Zimbabwe, with limited participation by provinces and districts (Government of Malawi 2011; Government of Zimbabwe 2009). The district officials who coordinate the response at district level in Zimbabwe and Malawi have limited involvement, if any, in the national contingency planning process. Some district officials contacted in Malawi and Zimbabwe were not sure whether a national contingency plan even existed. National disaster authorities in Zimbabwe and Malawi often support responses at district level, but rarely follow the national contingency plan's guidance. In many ways, the national contingency plan document is left on a shelf, suggesting that Zimbabwe's and Malawi's contingency planning systems tend to be fragmented.

Whilst contingency plans are designed mainly to strengthen coordination for preparedness and response, the results from Malawi, Namibia and Zimbabwe show that the practice is different. NGOs that work at district level develop their own plans, which in most cases are rarely informed by the national plans. The ideal situation is that lower-level contingency plans should dovetail with the national plan, with the national plan providing the guiding framework. This is the case in Mozambique, where organisations working at sub-national level developed guidelines and plans that informed the formulation of the national contingency plan (Government of Mozambique 2011). Discussions with participants during reviews in Mozambique revealed that because the process promoted transparency and mutual trust between the national and local levels, it strengthened a coordinated response.

In Namibia, Zimbabwe and Malawi, the coordination structures proposed in the contingency plan rarely reflect the national preparedness coordination structures. As Zimbabwe was experiencing a humanitarian crisis during the time of this study, the contingency response plans were based on United Nations cluster coordination mechanisms. The clusters such as agriculture, health, nutrition and education, and water, sanitation and hygiene were led by the United Nations agencies. Although the national disaster plan and the Civil Protection Act have clearly defined national committees, links with UN-led clusters that dominated sector response plans were unclear. In Mozambique and Zambia, the coordination structures are strongly linked to national structures, with contingency planning and coordination structures clearly embedded within government-led structures (Government of Mozambique 2008; Government of Zambia 2009). Further, interviews with participants in Mozambique and Zambia suggested that the contingency planning processes in these countries adopted a participatory and multisectoral approach, with clear roles and responsibilities for roleplayers. Without clearly outlined guidelines and coordination mechanisms, the implementation of contingency plans becomes fragmented. Parallel coordination structures, mostly led by United Nations agencies and other humanitarian organisations, tend to duplicate effort, thus creating confusion.

\section{Contingency planning and preparedness strengthening}

Contingency planning identifies hazards and vulnerabilities that are likely to interact to cause a disaster (Blaikie et al. 1994). Lack of comprehensive risk analysis and unrealistic parameters that inform scenario development can potentially pose difficulties for implementing contingency plans. To a certain extent, some contingency plans tend to be reactive as they are developed once there are already signs of a disaster looming.

Data from both secondary and primary sources revealed that the contingency plans from the five countries provide basic and generalised flood and drought risk analysis. The key issues highlighted in the risk analysis include hazard identification, vulnerable groups and possible disaster impacts. However, the depth of analysis varied in all five countries. In Mozambique, the number of people who were likely to be affected by floods under the best-case, middlecase and worst-case scenarios for floods (see Table 1) was calculated at provincial level. However, there was a lack of further detailed information indicating the areas within the province that were likely to be affected by the floods. Also, there was a missing link between the sectors and numbers of people who were likely to be affected. The term 'people likely to be affected' is used in all countries, without clarity on what the phrase means. In Zimbabwe, there was an 
attempt to give a breakdown of people affected to include children, and pregnant or lactating mothers (Government of Zimbabwe 2006, 2009). However, the number of 'people likely to be affected' did not change during the rainy season despite changing population patterns and other drivers of vulnerability.

A comparison of seasonal forecasts including identified hazards and developed scenarios tended to be generic, and scenarios were rarely updated to reflect projected and changing rainfall patterns. Neither the 2009-2010 nor the 2011-2012 contingency plans for Zambia, Namibia, Malawi and Zimbabwe were updated even after the forecast issued by the Southern Africa Climate Service Centre showed marked changes in expected rainfall in different parts of the southern African region (Southern African Development Community Climate Services Centre 2009a, 2009b, 2011, 2012). The same response plans, and the number of people likely to be affected, were maintained throughout the rainy season, thus making the plan of little use for the responders' purposes. Most of the hazards continuously change, hence the need for frequent reviews of the initial scenarios. This would ensure that the plan becomes a living document and could, in many ways, reinforce the view that contingency planning is a process rather than an event. The situation is made more difficult by the lack of hydrological data, which is an important input in flood forecasting. Scenarios and risk analysis tend to be primarily based on weather forecasts, with little or no consideration of other factors that may exacerbate flooding, such as basin characteristics, soil moisture conditions and current river discharge and flow regimes.

Namibia's regional plans for the Kavango and Caprivi regions along the Zambezi River also rely mainly on the regional weather forecast (Government of Namibia 2009) and rarely considers hydrological data. For example, changes in the discharge of the Zambezi River upstream, which affects flooding downstream in the Caprivi region, are not often reflected in scenario updates. In this way, the plan becomes a one-off event rather than a process. The plans for all five countries clearly identify the hazards such as floods, cyclones, dry spells and epidemics, but tend to lack vulnerability analysis. There was a tendency to cluster vulnerability as vulnerability indicators were not disaggregated by age, gender and disability. Similarly, there were unclear linkages between the overall number of 'people likely to be affected' and projected sector impacts.

Risk assessment, hazard detection and prediction, communication and dissemination, public awareness and coordination are some of the key fundamental components of an effective early-warning system for hydro-meteorological hazards (O'Neil 1997). Disaster preparedness does not entail only the development of early-warning information systems but also the dissemination of early-warning information. Whilst all contingency plans from 2008 to 2012 refer to earlywarning information, the challenge is that early-warning systems are either underdeveloped or non-existent. Some participants noted that underdeveloped or non-existent early-warning systems could have been a result of lack of clarity on what an early-warning information system should entail as well as limited understanding of vulnerabilities and capacities. People affected by floods in the five countries have diverse socio-economic situations and linguistic differences. National radio and television were used as the main means of disseminating early-warning information; however, not only was there poor radio transmission and reception in some of the areas affected by floods but it was also unclear whether people owned a radio or a television set. People along the Save River in Zimbabwe, which is affected mostly by floods, tend to listen to South African rather than local radio stations. This means that information disseminated through the national radio stations in Zimbabwe may not reach some of the marginal areas, where most of the vulnerable people live. Further, the information was disseminated in the main national languages (Shona, Ndebele and English), yet most of the people in the south-eastern districts of Zimbabwe speak Tsonga, which is one of the minority languages in the country. A comprehensive risk analysis could indicate distinct vulnerabilities and capacities as determined by sociocultural factors, which could strengthen the implementation of the contingency plan by making it relevant to the multiple contexts.

What is clearly discernible from the study is that the plans from all five countries include strong hazard identification, but pay little attention to vulnerability and capacity analysis. This predominance of the hazard approach could arguably be associated with the traditional 'command-and-control' management approach, a common feature in some of the countries' legislative frameworks for reducing disaster risk. Disaster legislation in Zimbabwe and Malawi are still strongly inclined towards traditional 'command-andcontrol' disaster management, with little reference to risk management. Namibia is still in the process of developing a legal framework for disaster risk management. The legislative framework should be central to informing lower-level planning that includes risk management and contingency planning. Lack of clarity of roles and responsibilities for lower-level roleplayers in the legislative framework may mean that contingency plans at this level risk being anchored on a weak foundation, making them difficult to implement.

The contingency plans from all five countries identified the prepositioning of relief items in strategic areas before flooding starts as one of the preparedness measures. This was meant to facilitate timely assistance to affected people as some of the areas may become inaccessible during disasters owing to poor road networks. However, several challenges exist. For Namibia, Malawi and Zimbabwe, the challenge relates to lack of finances needed to purchase stocks for prepositioning as the contingency plan does not include a budget for this. With high levels of chronic vulnerability in some of the countries, governments and partner organisations were reluctant to set aside financial resources for an event that possibly would not 
occur. Defining the tipping point that distinguishes chronic and acute vulnerabilities in most countries in southern Africa has been a major challenge. Indeed, the authors of this article feel that it is not always easy to determine the point when a problem perceived to be common or obvious can occur above the threshold, which would qualify it as an emergency or disaster.

With the five countries sharing a common river system and all being affected by flooding of the Zambezi River, it is worth noting that none of the scenarios and risk analyses consider cross-border issues. Information from neighbouring countries such as Angola, which includes river discharge levels and rainfall forecasts, were rarely used to forecast hazard trends for contingency planning by countries downstream along the Zambezi (Mozambique, Namibia and Zimbabwe). There was also barely any regional system in place to develop and disseminate a basin-wide early warning to all the countries affected by flooding of the Zambezi River. The situation was exacerbated by a poor network of hydrological gauging stations and recording instruments providing real-time data, especially from remote locations.

\section{Gaps in contingency planning}

There were recurring gaps in contingency planning across the five countries, namely limited financial resources and challenges in prompt release of field assessment results. One of the gaps in the contingency plans of Namibia and Zimbabwe was related to budget allocation for both preparedness and response. Financial resources were inadequate not only for preparedness activities but also for response, particularly for procurement of relief materials. Owing to inadequate budget allocation, the responses were not carried out in a timely manner in Namibia, Malawi or Zambia during 2008 and 2009 floods. It should be noted that in theory, contingency plans have budgetary allocations; however, in practice barely any financial resources are allocated. For example, in 2009 the regional plan for the Caprivi region in Namibia had a budget of N\$7 million, but it was not clear whether there was any actual allocation from the central government.

In contrast, the Mozambican government allocated a budget to cover most of the contingency planning and implementation processes. In 2010, the government of Mozambique allocated an equivalent of $\$ 4$ million to cover preparedness and response for the period 20122013 (Mozambique Humanitarian Country Team 2010). Consequently, when the country was hit by three cyclones and several floods in the period 2012-2013, Mozambique did not request international assistance as there were adequate funds allocated for the purpose. Other non-government organisations contributed to the budget shortfall to support the government (Mozambique Humanitarian Country Team 2010). As a result, Mozambique was able to, amongst other, (1) test national and local preparedness plans through simulation exercises and (2) pre-position stocks strategically in areas that were likely to be inaccessible during floods and this helped the timely delivery of assistance. The simulations involved multiple stakeholders who later implemented the plan, which made it possible for them to identify and address their weaknesses. The government also invited experts in preparedness and response from outside the region to provide a critical appraisal of the simulation. This helped to strengthen the national and regional contingency plans.

During flood responses, rapid assessments and the prompt release of assessment results are deemed essential. Contingency planning processes also develop assessment tools and a multisector assessment team is usually set up. Essentially, the team should be well trained in assessment and ready for field assessments in the shortest possible time. Assessments are also linked to other information management systems required for effective response, such as data processing, analysis and reporting. The tendency has been for the contingency planning to look at information management not as a system, but as a one-off intervention. This has resulted in challenges in data processing, with little clarity with regard to not only data capturing and analysis approaches but also the kind of outputs expected from the analyses. Also, the time taken during field assessments rarely meets the international standards, which state that field assessments should be conducted during the first week of the emergency (Inter-Agency Standing Committee 2007; International Federation of Red Cross and Red Crescent Societies 2007). During the 2009 floods in Namibia, the disaster assessment lasted for more than 2 weeks, with the results made available only after another 3 weeks (Government of Namibia 2009). In this case, the results were of little value for an emergency response. Similarly, during the 2008 flood season in Zambia, it took close to 3 weeks to have the disaster assessment results released.

The assessment reports tended to be general; they did not necessarily target specific response sectors. In most cases, different response sectors require different sets of information to support their responses. Senior government authorities may not have the time to read lengthy, untargeted reports, whilst donors have specific information requirements to enable them to provide appropriate resources. Agencies also tend to carry out their own assessments in cases where a common multisector tool has not been developed and agreed to in advance, as was the case in Namibia in 2009. As a result, too many agencies can conduct field assessments involving the same group of affected people, who may develop assessment fatigue.

\section{Conclusion}

Using case material from Malawi, Mozambique, Namibia, Zambia and Zimbabwe, this study suggests that contingency planning can be a complex process. The findings are grouped into three categories. Firstly, there appears to be a wide gap between theory and practice in contingency planning. The contingency plans tend to be skewed towards hazards, with limited attention to vulnerabilities and capacities. This is despite the HFA being one of the policy guidelines that shifts disaster causation from environmental determinism (acts 
of God and Nature) (Middleton \& O'Keefe 1998) to social construction, where disasters are viewed as acts of humans (Furedi 2007; Wijkman \& Timberlake 1984). This suggests that the much cited 'at risk equation' has not necessarily informed contingency planning in southern African countries. There appear to be system challenges in hazard, vulnerability and capacity analysis to develop comprehensive contingency plans that reduce the impact of a disaster. Secondly, response activities rarely reflect projected scenarios. The contingency plans are not necessarily based on comprehensive risk analysis to inform scenario building. Basic risk analysis rarely reflects the changing nature of risk over time. In this case, contingency plans are of little value, as there tend to be discrepancies between the contingency plan and the response plan when the disaster happens. Thirdly, although Mozambique has seen an improvement in the allocation of resources, contingency planning is under-resourced in the other sampled countries. Yet, response plans, which tend to be informed by contingency plans, require strategic positioning of resources, training and simulation exercises, dissemination of information and broad-based participation before the onset of a disaster. Underlying the resource challenges are generally outdated legal and institutional frameworks, despite disaster management having changed dramatically, particularly following the adoption of the HFA in 2005. In this way, disaster risk reduction has not necessarily shifted towards proactive management of disasters.

We conclude that unless these issues are addressed, contingency planning is likely to remain theoretical, rather than a practical tool for building disaster-resilient communities in southern African countries.

\section{Acknowledgements Competing interests}

The authors declare that they have no financial or personal relationship(s) that may have inappropriately influenced them in writing this article.

\section{Authors' contributions}

E.M. (Bindura University of Science Education) was responsible for the overall design and implementation of the study. S.B.M. (Northumbria University) was responsible for the literature review and the analytical framework of the study.

\section{References}

Blaikie, P., Wisner, B., Cannon, T. \& Davis, I., 1994, At risk: Natural hazards, people's vulnerability and disasters, Routledge, London. PMid:7798194

Choularton, R., 2007, Contingency planning and humanitarian action: A review of practice, Overseas Development Institute, London.

Eriksson, K. \& McConnell, A., 2011, 'Contingency planning for crisis management: Recipe for success or political fantasy?', Policy and Society 30(2), 89-99. http:// Recipe for success or political fantasy?', Poli
dx.doi.org/10.1016/j.polsoc.2011.03.004

Furedi, F., 2007, 'The changing meaning of disaster', Area 39(4), 482-489. http:// dx.doi.org/10.1111/j.1475-4762.2007.00764.x

Government of Malawi, 2011, National contingency plan 2011-2012, Department of Disaster Management Affairs, Lilongwe.
Government of Mozambique, 2008, Mozambique vulnerability analysis, Technical Secretariat for Food Security and Nutrition, Maputo.

Government of Mozambique, 2011, Republic of Mozambique contingency plan for rainy and cyclone season 2011-2012, National Disaster Management Institute, Maputo.

Government of Namibia, 2009, 'Report on the 2009 flood disaster response', Directorate Disaster Management, Windhoek.

Government of Zambia, 2009, National contingency plan: 2009-2010, Disaster Management and Mitigation Unit, Lusaka.

Government of Zimbabwe, 2006, Inter-agency national contingency plan: 2006-2007, Office for the Coordination of Humanitarian Affairs, Harare.

Government of Zimbabwe, 2009, Inter-agency contingency plan: 2009-2010, Office for the Coordination of Humanitarian Affairs, Harare.

Guba, E.G. \& Lincoln, Y.S., 2005, 'Paradigmatic controversies, contradictions and emerging confluences', in N.K. Denzin \& Y.S. Lincoln (eds.), Qualitative research, 3rd edn., n.p., Sage, London.

Harding, J., 2013, Qualitative data analysis from start to finish, Sage, London.

Harrald, J. \& Mazzuchi, T., 1993, 'Planning for success: A scenariobased approach to contingency planning using expert judgment', Journal of Contingencies and Crisis Management 1(4), 189-198. http://dx.doi.org/10.1111/j.1468-5973.1993. tb00109.x

Inter-Agency Standing Committee (IASC), 2007, Inter-agency contingency planning guidelines for humanitarian assistance, IASC, Geneva.

International Council for Science (ICSU), 2007, Natural and human-induced hazards and disasters in sub-Saharan Africa, ICSU Regional Office for Africa Science Plan, Seychelles, 05-06 March.

International Federation of Red Cross and Red Crescent Societies (IFRC), 2007, Disaster response and contingency planning guide, IFRC, Geneva.

Manyena, S.B., O'Brien, G., O'Keefe, P. \& Rose, J., 2011, 'Disaster resilience: A bounce back or bounce forward ability?', Local Environment 16(5), 417-424. http:// dx.doi.org/10.1080/13549839.2011.583049

May, T., 2011, Social Research, Open University Press, Milton Keynes.

Middleton, N. \& O'Keefe, P., 1998, Disaster and development: The politics of humanitarian aid, Pluto Press, London.

Mozambique Humanitarian Country Team, 2010, Emergency preparedness and response needs related to drought, Inited Nations Development Programme, Maputo.

Office for the Coordination of Humanitarian Affairs, Regional Office for Southern Africa (OCHA-ROSA), 2012, OCHA, Johannesburg.

O'Neil, D., 1997, International Decade Natural Disaster Reduction (IDNDR) early warning program: Report on early warning for hydro-meteorological hazards including drought, International Decade Natural Disaster Reduction, Geneva.

Patton, M.Q., 2002, Qualitative research and evaluation methods, Sage, London.

Ragin, C., 1987, The comparative method: Moving beyond qualitative and quantitative strategies, University of California Press, Berkeley. PMid:3664130

Southern African Development Community (SADC), 2012, Policy paper on climate change, SADC, Gaborone.

Sarantakos, S., 2006, Social research, Palgrave, Hampshire.

Schedler, A., 2007, 'Mapping contingency', in I. Shapiro \& S. Bedi (eds.), Political contingency: Studying the unexpected, the accidental, and the unforeseen, $\mathrm{pp}$. 54-78, New York University Press, New York.

Southern African Development Community Climate Services Centre (SADC CSC) 2009a, Rainfall forecast January-March 2009, Issue no. 3, SADC CSC, Gaborone.

Southern African Development Community Climate Services Centre (SADC CSC), 2009b, Rainfall forecast February-April 2009, Issue no. 4, SADC CSC, Gaborone.

Southern African Development Community Climate Services Centre (SADC CSC), 2011, Rainfall forecast December 2011-February 2012, Issue no. 2, SADC CSC, Gaborone.

Southern African Development Community Climate Services Centre (SADC CSC), 2012, Rainfall forecast March-May 2012, Issue no. 5, SADC CSC, Gaborone.

United Nations Development Programme (UNDP), 2012, Institutional capacity assessment in disaster risk reduction of SADC, SADC, Gaborone.

United Nations High Commissioner for Refugees (UNHCR), 2003, Contingency planning for emergencies: A manual for local government units, National Disaster Coordination Council, Manila.

United Nations International Strategy for Disaster Reduction (UNISDR), 2005, Building the resilience of nations and communities to disasters: Hyogo Framework for Action 2005-2015, UNISDR, Geneva.

United Nations International Strategy for Disaster Reduction (UNISDR), 2007, Words into action: A guide for implementing the Hyogo Framework, UNISDR, Geneva.

United Nations International Strategy for Disaster Reduction (UNISDR), 2009, Terminology on disaster risk reduction, UNISDR, Geneva.

Wijkman, A. \& Timberlake, L., 1984, Natural disasters: Acts of God or acts of man?, Earthscan, London. 